\title{
Attuning: A Communication Process between People with Severe and Profound Intellectual Disability and Their Interaction Partners
}

\author{
Colin Griffiths* and Martine Smith ${ }^{\dagger}$ \\ *The School of Nursing and Midwifery, Trinity College, Dublin, Ireland; ${ }^{\dagger}$ School of Linguistic, Speech and Communication Sciences, Trinity \\ College, Dublin, Ireland
}

Background People with severe and profound intellectual disability typically demonstrate a limited ability to communicate effectively. Most of their communications are non-verbal, often idiosyncratic and ambiguous. This article aims to identify the process that regulates communications of this group of people with others and to describe the methodological approach that was used to achieve this.

Materials and Methods In this qualitative study, two dyads consisting of a person with severe or profound intellectual and multiple disability and a teacher or carer were filmed as they engaged in school-based activities. Two 1-hour videotapes were transcribed and analysed using grounded theory.
Results Attuning was identified within the theory proposed here as a central process that calibrates and regulates communication.

Conclusion Attuning is conceptualized as a bidirectional, dyadic communication process. Understanding this process may support more effective communication between people with severe or profound intellectual and multiple disability and their interaction partners.

Keywords: attuning, communication, profound intellectual disability

\section{Introduction}

People with profound intellectual and multiple disabilities (PIMD) need extensive supports to engage meaningfully with life and to take up the daily activities that people without disabilities engage in ordinarily (Hughes et al. 2011). Such supports are required because their disabilities often make it difficult to determine their capacities (Nakken \& Vlaskamp 2007). As a consequence, a communication gulf can emerge between persons with intellectual disability and those who care for, educate and support them. This gulf can be characterized by mutual misunderstanding in interactions involving people with PIMD and those with whom they come into contact. An illustration of this is the well-documented use of complex verbal language by staff interacting with service users (Bradshaw 2001; Healy \& Noonan-Walsh 2007), language that is not likely to be understood by the communication partner with intellectual disability. Similarly, people without disabilities often experience difficulties in interpreting the communications of people with PIMD (Grove et al. 1999), partly due to the idiosyncratic nature of such communications and the lack of verbal communication.

This paper aims to achieve two goals. First, it sets out to describe 'attuning', a process advanced as a mechanism that illuminates communication between people with severe and profound intellectual and multiple disability and others. The second aim is to describe the qualitative methodology that was used to develop the concept of attuning and to explicate the interpretive framework that enabled data collection and analysis.

Attuning as described in this study can be construed as a mechanism or process that enables potential communicators to unravel the communication conundrum 
that so often confounds interactions involving people with severe and profound intellectual disability. Achieving such a goal may facilitate more satisfying and sustainable interactions and thereby positively impact both participants in such interactions.

\section{The Nature of Communications for People with Profound Intellectual and Multiple Disability}

For the most part, the capacity to communicate verbally is not available to people with PIMD (Hogg et al. 2001). Most of their communications are non-symbolic (McLean et al. 1999), that is, they are not based on representational systems linked to a shared common code, such as signing systems or explicitly indicative gestures. They rely on contact gestures rather than distal (non contact) gestures (McLean et al. 1991), as well as facial expressions, body movements and vocalizations (Stephenson \& Dowrick 2005), gestures (McLean et al. 1999), body direction, eye gaze and actions (Bradshaw 2001). It has long been argued that the symbolic constraints outlined above are not modality-specific, but rather that people with PIMD have a limited ability to use a formal linguistic code in any modality' (e.g., Grove et al. 1999:190).

Despite the agreement within the literature on the extent of communication challenges faced by those with PIMD, it is also important to acknowledge the heterogeneity of this group. Predicting communication abilities on the basis of global measures of cognitive functioning is fraught with difficulties. Individuals with a severe intellectual impairment may well be able to use some symbolic communication (e.g., Johnson et al. 2011), unlike their peers with a more profound intellectual disability. However, in the absence of definitive evidence in the research literature that describes how interaction for people with limited formal communication abilities takes place, it seems plausible that interaction involving any person with very limited symbolic functioning places unusual demands on the communication process. Even skilled communicators may find themselves challenged to support mutually enriching interactions in dyads where their partner's communication skills are largely non-symbolic. For this reason, within this study, the focus is on participants who communicate primarily through non-symbolic communications, and whose overall level of cognitive functioning is within the severe-profound level of intellectual disability.

In the light of factors outlined above, it is clear that many people with severe and profound intellectual disability (S/PIMD) experience difficulty in achieving mutually rewarding communication interactions (Hostyn \& Maes 2009). Understanding the factors that support successful communication interactions is important in seeking to enhance the communication experiences of both partners in dyads comprising people with S/PIMD and those with whom they come into contact. Considerable work has been undertaken to enhance the interaction experiences of people with intellectual impairment, through focusing on the environment, rather than the individual with PIMD (e.g., Bunning 1996). Bunning's work suggests that the nature of the environment impacts on the behaviours of people with PIMD and that the careful application of individually designed sensory stimulation programmes has the effect of reducing the level of 'self-active' behaviours (stereotypical behaviours). However, Bunning points out that the involvement of people who have a significant role in the lives of those with PIMD is important in the success of a sensory intervention (Bunning 1998). This suggests that enhancing communication success rests on attending not only to the environment but also to the role of those who know and 'understand' the person with PIMD within that environment (Bunning 1998). The importance of such close and familiar communication partnerships is echoed in the work of Johnson et al. (2012).

\section{The Dyadic Nature of Communication}

The essence of communication is that it is a process where two or more persons cooperate to make mutual meaning (the 'cooperative principle' of Grice (1999)), a partnership where ideas are exchanged and meanings interpreted (Bradshaw 2001). Interpersonal communication may be construed as a dynamic feedback process where signals or messages are continuously sent, interpreted and responded to in an ongoing loop. Mutual understanding rests on attaining a shared understanding of the interpretation to be ascribed to signals that is, an empathic understanding.

Hewett \& Nind (1998) describe empathy as a key quality that infuses the practice of staff who wish to work in an ethical manner with people with an intellectual disability. In their commentary on interactive approaches to Intensive Interaction, they define empathy as 'a perspective on what the world may be like for people with learning disabilities' (Hewett \& Nind 1998:18). A similar emotional engagement and closeness emerged in Forster \& Iacono's (2008) study of three disability support workers' views of how they interacted with a woman 
with PIMD. Two elements stood out as foundations to these interactions: the attachment between staff and service user and the strong emotional component inherent in that attachment. Empathic understanding is also demonstrated in Firth et al.'s (2010) consideration of Intensive Interaction. These authors describe a state of 'being with' the other person, attuned to the other, where a state of 'mutually pleasurable and symmetrical sociability' (Firth et al. 2010:58) exists between the staff member or teacher and the person with profound intellectual and multiple disability. Affective attunement is a phenomenon closely related to empathy. Stern (1985) defines affective attunement as 'the performance of behaviours that express the quality of feeling of a shared affect state without imitating the exact behavioural expression of the inner state' (Stern 1985:142). This meeting of minds is described in Forster's analysis of how disability support workers perceive their interactions with people with PIMD. She defines the concept of affect attunement as comprising a matching of vocal, facial, postural and gestural behaviours in terms of their rhythm, duration, intensity and shape (Forster 2011).

Mutual understanding appears to be the aim of good dyadic communication, this involves an affective sharing that is comprehensible to the communication partner, through a process of continuously attempting to see the world from their perspective to truly 'understand' the communication.

\section{The Interpretation of Communication}

Attaining a level of understanding of reciprocal interactions is an important factor that affects the quality of life of persons with PIMD (Hostyn et al. 2011). If a person's communications cannot be easily understood, that person's ability to express how he or she feels, explain what he or she may want and ultimately have an effect on the environment in which life takes place, is severely constrained. However, dyadic communication is by definition bidirectional: if neither communicator recognizes what the other is 'saying' it is difficult to establish a dialogue. Each participant may attribute responsibility for the 'misinterpretation' of communication to their communication partner (Coia and Handley 2008). The interpretation of communication rests on two principles. The first is that communicators assume that meaning exists in the other person's behaviour (Kaiser \& Goetz 1993). The second is that interpretation of meaning is fluid and dynamic. Interpretations cannot simply be categorized as 'correct' or 'incorrect'. Rather interpretations exist along a continuum, at one end achieving a fully shared interpretation and at the other, a lack of any shared or agreed interpretation. Certain factors may make it more or less likely that interpretations of meanings align across partners, in a sense propelling the interpretation towards the accurate end of the axis of understanding. The identification of one factor, (perhaps the overarching factor) in promoting aligned interpretations of communication in this process, is the subject of this study.

\section{Materials and Methods}

\section{Design}

The research study aimed to answer the question: how do people with severe and profound intellectual and multiple disability interact with those with whom they come into contact? The obverse question was also asked, namely, how do people without intellectual disability interact with those with severe and profound intellectual disability? The study set out to achieve this aim by developing a theory that would explain the interaction process between people with severe and profound intellectual and multiple disability and others with whom they interact. The study was designed as an observational study, gathering qualitative data that would be analysed using grounded theory. The research site was located in a developmental disability centre (DDC) in Ireland. This is a non-residential school for children and young adults with severe and profound intellectual disability. Ethical permission for the research was obtained from the University Health Sciences Research Ethics Committee and from the ethics committee of the service provider. All participants consented to participate in the study, either directly or indirectly through written proxy consent from parents or grandparents for those participants with intellectual disability.

\section{Participants}

A purposeful sampling strategy was used to recruit three dyads each comprising one participant with intellectual disability and that person's keyworker. Data from two of these dyads are reported here. Data from dyad 3 were not analysed for this study as data saturation was achieved based on the selected observations from dyads 1 and 2. Dyad 1 consisted of JM (pseudonym John) an 18-year-old man. John could 
walk but his gait was quite unsteady; he could vocalize but had no recognizable spoken words. John had epilepsy and was assessed as having a profound intellectual disability. John's keyworker, Kate was a childcare worker in her twenties, who had known him for 1 year. Dyad two consisted of TK (pseudonym Tony), a 26-year-old man who had a diagnosis of quadriplegic cerebral palsy. Tony could vocalize but had no consistently recognizable words. Tony was assessed as having a borderline severe/profound intellectual disability. Tony was a non-symbolic communicator. He had sufficient hand function to use some movements that at times were interpreted as gestures, but these were neither consistent nor transparent. Mary his keyworker was a nurse in her fifties. She had known him for over a year. Formal assessment of communication abilities was not undertaken, primarily because the focus was on how interactions between the specific communication partners within each dyad were constructed and managed. As such, the communication abilities of interest were those abilities of both partners as interpreted by the communication partner, rather than as referenced to other contexts or standards.

The keyworkers described above organized and took part in the activity sessions that provided the data for this study. The keyworkers knew the service users well and it was evident that a strong positive relationship existed between the members of each dyad - paralleling the emotional attachment described by Forster \& Iacono (2008) and Johnson et al. (2012). A number of other staff also participated in the activities either directly or indirectly, notably $\mathrm{Al}$ (pseudonyms are used throughout) a teacher who directed some of the group activities.

\section{Procedures}

This was an observational study where video was the primary data-gathering tool. Although field notes were also made, these were addenda to the video-derived data. Each of the participants was filmed for 1 hour on the basis that this would enable a variety of activities to be observed and that each particular activity could be filmed for a sufficiently long period (10-20 min) to allow sequences of interactions to become apparent. These activities took place as part of the usual school timetable and included being fed, painting, playing oneon-one games, motor movement exercises, group games and group stories, as well as some interactions that were simply social dialogues. The particular activities were chosen because they represented periods when interaction between staff and students was at its most frequent. All activities included at least one staff member, with most interactions involving a person with PIMD and their keyworker.

Preparations for filming involved spending time in the preceding weeks with students and staff in the DDC and ensuring that the camera was set up before students and staff arrived on the filming days. The films were made using a JVC GR-D240 digital video camera. The action was recorded to videotape and downloaded to a laptop computer. The data were handled using Ulead Video studio 7 (Corel Corporation, Ottawa, Ontario, Canada), a video editing package. This software enabled the film to be run at any required speed, run backwards and run on a frame-by-frame basis ( 24 frames per second) to enable detailed transcription.

The process of transcription involved selecting a format for translating the data from the dynamic format of a video to a static two-dimensional representation. One of the challenges of working with video is balancing the risk of data overload while capturing the level of detail that provides access to useful data for analysis. As Ochs (1979) points out, transcriptions become the researcher's data - the basis for all future analysis, shaping the questions that can be addressed (see also Garman 1989; Fletcher \& Garman 1995). To ensure that the data transcribed would allow exploration of communication behaviours, all recordings were initially reviewed to identify segments incorporating interpersonal interaction between at least two participants. These segments were then selected for fine-grained transcription for later analysis. The aim was to construct a highly detailed narrative picture, capturing micro- and macrobehaviours of all the participants. In total, $25 \mathrm{~min}$ of selected action from the 2 hours of recorded data of Tony-Mary and of JohnKate were transcribed.

A transcription framework was developed to capture the verbal and non-verbal behaviours of participants as they occurred on a second-by-second basis. In some instances actions were further subdivided, delineated and numbered using frame-by-frame analysis. This permitted actions to be enumerated at a detail of $1 / 24$ th of a second revealing a potential 36000 data points across the 25-min video recording. Such detailed analysis enabled close observation of minute micromovements, such as each person's saccades (rapid ballistic changes in eye position that occur three to four times per second). The framework consisted of six columns which recorded the exact time (hour/minute/ 
second/fraction of second) of the incident, the nonverbal and the verbal actions of both participants and any comments on the action in each row. The next row recorded the same data for the following second, thus building up a second-by-second description of the entire interaction process. This process enabled the development of a detailed narrative attaining Schonfeld's goal of explaining 'at a particular grain size every action and utterance' (Schonfeld 1992:205). As a consequence of this very detailed transcription process, each minute of interaction yielded many pages of interaction detail, capturing overlapping layers of multimodal communication, for both participants in interaction sequences.

\section{Data analysis}

Grounded theory methodologies have a well-established tradition in research focusing on the analysis of 'talk'. 'The Discovery of Grounded Theory' (Glaser \& Strauss 1967) outlined a method whereby the inherent patterns in primarily qualitative data could be identified. The emergent approach to data analysis as applied in this study relied on the naming of codes based on the written data and the constant comparison of those codes with each line of data as it was analysed. Thus, codes were named and renamed through comparison with the content and name of existing codes. Ultimately memos were written to identify the theoretical relationships between categories in the data, so that a 'symbiotic relationship between data and theorizing is advanced' (Duchscher \& Morgan 2004:607) ensuring a close fit between theory and the data sources.

There are several different schools of grounded theory. All aim to develop theory from qualitative data through a process of coding, categorizing and modelling relationships across the data; however, the degree to which they adhere to the original vision differs. Three traditions within the grounded theory schools are most prominent. Kathy Charmaz's constructivist approach views grounded theory as a flexible set of principles for data analysis (Charmaz 2006) rather than as a prescriptive methodology. In this view, data analysis is an interpretive process and therefore analysed data are by definition co-constructed by the grounded theorist. Strauss \& Corbin (1990) propose a structured data analysis framework whereby after initial coding of the data, a theoretical framework is developed through axial coding linking categories around their axes, and the use of a coding device called the conditional/consequential matrix. Glaser (1998) eschews such a structured approach to analysis, on the grounds that imposing such structure may force the analysis in ways that may distort the findings. He also regards constructivism as espoused by Charmaz (2006) as a variation on method for which there is no justification. Glaser accepts the researcher's role in data analysis, but contends that through constantly returning to the data to ascertain if the emergent theory accurately reflects the data, the role of the researcher can be neutralized (Glaser 1998). Such neutralization requires the researcher to bracket his or her preconceptions and insist on adopting a stance of 'unknowing' until the theory emerges. Thus, of these three major approaches, a Glaserian approach places the greatest emphasis on the importance of data-driven theory construction, unfettered by structural analysis constraints. The key element is that analysis should not be 'forced' so the relationships within the data that emerge truly reflect what is going on in it (Glaser 1998). One aim in the research reported here was to apply a Glaserian approach to analysis of the narrative transcripts that had been developed, recognizing that much of the data to be analysed fell outside the boundaries of traditional conceptions of 'talk'. In the study reported here, the first author completed all stages of coding and analysis.

The first step, coding, involved constant comparison. Following identification of the first code, the next piece of data identified was compared with it, to ascertain its similarity or otherwise to the initial code. If it was similar it was incorporated in the first code; if different, a second code was named. Initial coding of the interaction data identified 242 codes. Simultaneously with the coding process, memos were written that identified potential relationships between the emerging codes and categories. The 242 codes were eventually merged into eight categories (concepts), by grouping initial codes that appeared to relate to similar concepts. These groups were then formed into named clusters. Clusters were subsequently reformed, (in some cases several times) as additional codes were added to each cluster in a constant iterative cycle. Eventually prospective names emerged. These clusters were developed to become the initial categories of the theory and these categories ultimately constituted the concepts of the theory (see Figure 1).

As with any analysis that involves the generation of codes or categories, one important goal was to attain data saturation. Data saturation occurs when the properties of the categories become well defined and the analysis of further data does not add to those properties or expand the definition of the categories. As data 


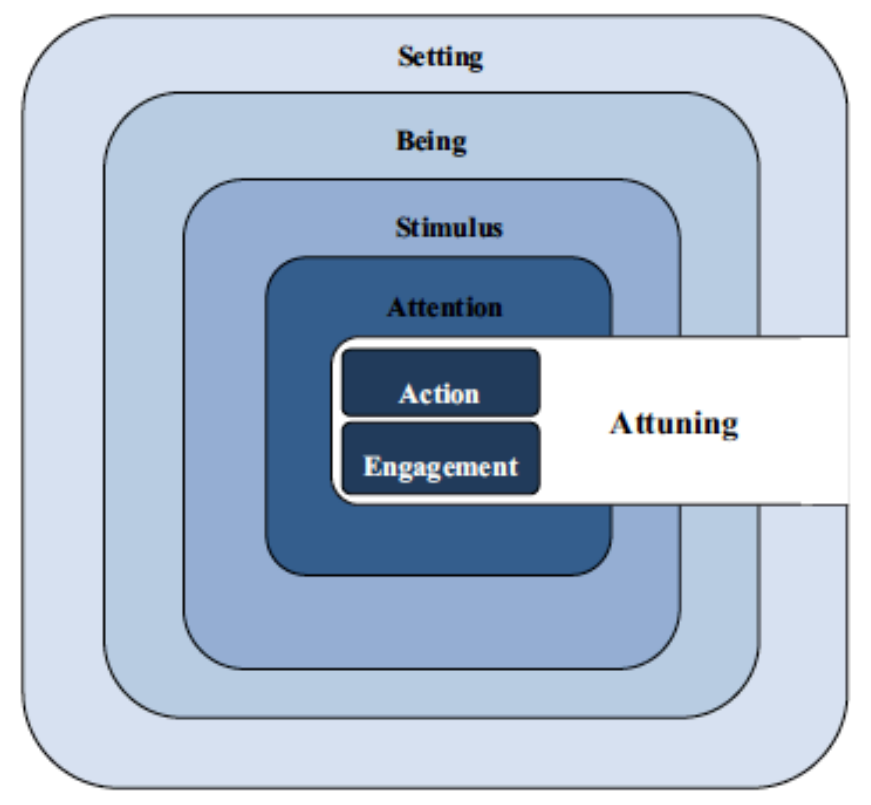

Figure I The theory of attuning.

analysis proceeded, when it became clear that the properties of a particular category were not defined consistently, or that the relationship between that category and other categories was not explicit, further theoretical sampling was undertaken. This involved returning to the field to take further observational field notes and in two instances conducting focus group interviews with key staff members. Ultimately, as the theoretical sampling process was completed, no further codes arose that clarified the properties of categories that had not until then achieved saturation. This meant that each category had achieved data saturation. As well as the development of the categories from the initial codes, over 200 memos were written during the data gathering, analysis and theoretical sampling processes. The coding process defined and identified the properties of each of the categories. The memos were written to identify possible relationships between the codes and the categories. The codes therefore named the categories and their properties (the vertical structures of the theory) while the memos identified how the categories of the theory were linked (the network structure of the theory). This analysis then led to the generation of the proposed core category of attuning, that is, the category that accounts for most of the data (Glaser 1998).

\section{The robustness of the data}

Grounded theory (GT) rests on the fundamental assumption that the theory that emerges from the research data fits that data (Glaser \& Strauss 1967). This assumption requires that the theory (the findings) reflects the incidents in the data and explains and accounts for the interactions that are under scrutiny. Four criteria operate as sources of trust in grounded theory (Glaser 1998): fit, relevance, work and modifiability. Fit is the GT equivalent of validity or trustworthiness. Evidence to support the fit of a theory to the data from which it was sourced lies in the assiduous application of the constant comparative method. Such evidence is to be found in the audit trail that was compiled from a research diary documenting the research process. Relevance rests on the extent to which the theory is actually applicable to the issues of the participants. Supporting evidence for the fit and relevance of the data rested on interviews with the staff members of each dyad, which took place after the initial analyses of the data, exploring the interpretations of certain behaviours, the accuracy of the coding process and relevance of the emerging concepts and core category. Some minor changes were made to some of the interpretations on the basis of the staff comments. However, where clear differences in interpretations occurred, staff interpretations were incorporated into the results until agreement was reached. Fit was also explored through the process of seeking further data saturation for categories that were underspecified from the original data set, through theoretical sampling of further video recordings. Finally, a theory can be said to work if practitioners find it useful in the field and it may have modifiability if it can be altered to accommodate new information. Both of these are posttheoretical tests that have yet to be applied.

Classic Glaserian grounded theory has rarely been applied to the analysis of qualitative descriptive data obtained through observation, and to our knowledge has been applied only once to interaction data of the kind reported here (Nilsson 2011), where non-verbal communication played a prominent role. The necessity for finding a way to elicit the meaning of interactions involving people with little access to conventional 'words' or 'talk' was the main driver for the development of the methodology. The use of grounded theory facilitated this. In the process, it turned out to be a methodology that provided a new way of discovering 'talk' that did not rely on words.

\section{Results}

The goal in any grounded theory analysis is to identify a core category, that is, a category that accounts for 
most of the data. The core category identified here is 'attuning', a process whereby communication partners move symmetrically or asymmetrically towards or away from each cognitively and emotionally. The theory suggests that attuning regulates communication. Attuning as the core category names the theory proposed here, but it is also the process that operates to regulate how communication takes place. The full theory is composed of seven related but discrete concepts: setting, being, stimulus, attention, action, engagement and attuning, with attuning representing the core category (see Figure 1).

\section{The theory of attuning}

The theory of attuning may be summed up in the following way: all communication takes place in the context of a physical setting. The setting influences the state of mind of the person in it (his or her sense of being). A person's state of mind influences what stimuli the person offers to another, who may attend to the stimulus or not. Attending to the stimulus is influenced by the setting in which the interaction takes place and the state of mind of the person attending to the stimulus. If the other attends to the stimulus, he or she may act or may become engaged with the first person. The determining factor is the process of attuning. Attuning affects and reflects how a communication partner feels and therefore whether he or she may offer a stimulus to a partner, attend to the other, engage with the other and then act. Whether a person attunes to another is determined by similar factors and of course the engagement process itself. All these processes feed back to both communication partners to influence their state of mind (being).

Attuning constitutes an implicit cognitive process that is not observable in itself. Nevertheless, within the data, there are observable behaviours that indicate that attuning is taking place:

- Two partners looking at each other.

- Movement towards the person/object to whom the partner is attuned.

- Eye contact

- Physical manifestation of assent such as a smile in reaction to a stimulus that has been offered by another partner.

- Close physical contact.

- Close psychological contact manifested by physical indicators such as smile, posture, gaze and expression.
- Smile or laughter indicating shared amusement at third person or object.

- Joint action.

- Mutual attention.

- An action or stimulus offered by one partner leading to a changed and more attuned state of being in the other partner.

\section{Structure of the theory}

Attuning therefore, as proposed here, is an active process that operates within communication partnerships, characterized by fluctuating levels of direct mental, emotional and physical closeness between the partners in a communication dyad. It is represented by two, two-dimensional continua, thus it has four dimensions. These continua can be considered as constituting two paired-opposite dimensions: empathy (which varies from the high empathy code of harmony to the low-empathic code of screaming) and cooperation (which varies from the high cooperation code of attuning dual to the low cooperation code of refusal). In essence how people attune to one another is manifested in the degree to which they empathize and cooperate with the other.

The theory further suggests that these continua operate independently. Because attuning is a dynamic, active process, levels of attuning between partners can vary at any point in communication, along both dimensions of empathy and cooperation. For example, partners may be highly attuned and empathic with each other and focused on a shared goal (high on both axes, see upper left quadrant A in Table 1 and Figure 2). However, partners may also be highly attuned to each other's 'state of mind' or wishes (high on the dimension of empathy), but disagree on a goal, leading to strong refusal incidents. One example, coded as defensive restraint, is illustrated by an incident where $\mathrm{Al}$ tries to hold John's hands to prevent him grabbing her waistcoat (JM9-8.52) (See upper right quadrant B; high on empathy but low on cooperation). Participants may also exhibit behaviours that code low on both axes (lower right quadrant D), in codes such as disconnected, an example of which is Tony looking at the camera while Mary is standing beside him, not looking at him but playing with a toy tiger (TK652.18-20). Further detail on both axes (empathy and cooperation) is provided below.

The framework is illustrated in Table 1 and Figure 2. 
Table I The structure of attuning

\begin{tabular}{lll}
\hline & Positive attuning & Negative attuning \\
\hline Pro-attuning & $\begin{array}{l}\text { Both partners are highly attuned to each other } \\
\text { and what they do and how they feel. There } \\
\text { is a sense of harmony regarding the } \\
\text { mutuality of their actions. }\end{array}$ & $\begin{array}{l}\text { Both partners are empathically attuned to } \\
\text { each other, they understand what the } \\
\text { other wishes, however, one or both does } \\
\text { not accede to the other's wishes. Good } \\
\text { mutual understanding is demonstrated } \\
\text { but cooperation is absent. }\end{array}$ \\
$\begin{array}{ll}\text { Anti-attuning } \\
\text { A low level of empathy is combined } \\
\text { with a high degree of cooperation } \\
\text { between the partners. Partners } \\
\text { may cooperate but in an } \\
\text { automatic manner that does not } \\
\text { indicate affective engagement. }\end{array}$ & $\begin{array}{l}\text { with little or no cooperation between the } \\
\text { partners. Strong disengagement characterizes } \\
\text { the concept such as where one partner is } \\
\text { distressed and the other does not connect to that. }\end{array}$ & \\
\hline
\end{tabular}

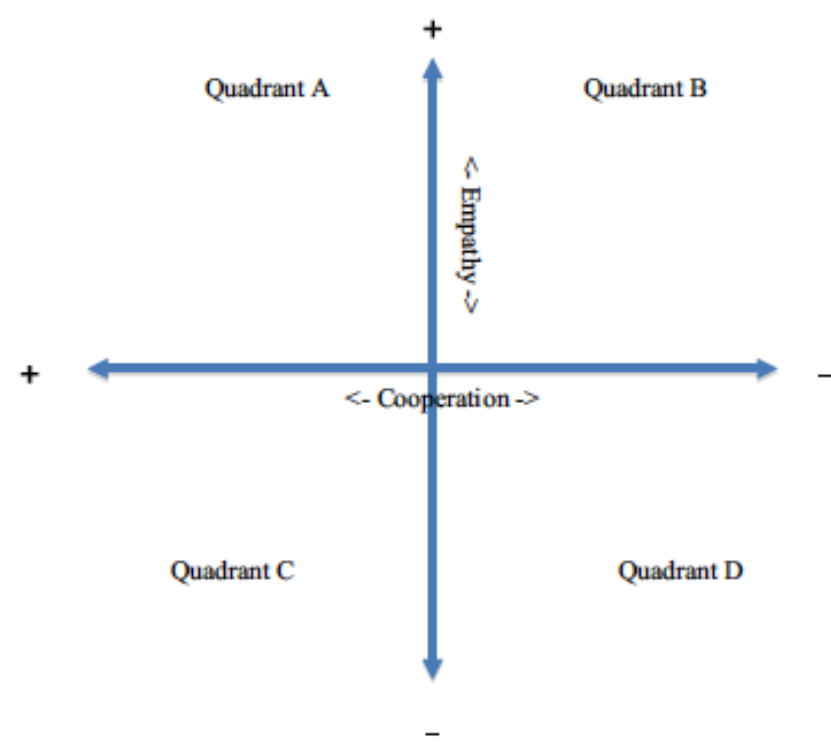

Figure 2 The Structure of Attuning

\section{Dimension I: Empathy}

The empathy dimension of attuning is concerned with calibration of mutual understanding and accord between the communication partners. Table 2 illustrates the ranked codes that constitute a continuum from a highly attuned state of harmony to a strongly disattuned state of screaming, on this axis of empathy.

The code harmony denotes the highest level of empathy and can be illustrated by two incidents. In one (TK1-9.33), Mary is feeding Tony. He opens his mouth as the spoon arrives, she inserts the spoon and he takes the food. Tony's anticipation of the spoon and his response to that anticipation (opening his mouth) allows the easy insertion of food, and a calm, rhythmic coordination of actions. A second illustration (JM9-8.368.42) suggests a silent accord. John is sitting on a mat, holding hands in silence with $\mathrm{Al}$ who is squatting on the mat beside him. This episode lasts for some seconds. A mid-ranking code such as assent is illustrated by a painting session with Tony and Mary. Initially, Tony is reluctant to participate but he finally allows Mary to push his hand onto the paper and start painting (TK758.07). The painting session continues as Tony's smile vanishes, his mouth opens and his face looks strained, leading to a contrasting code upset characterized by a negative emotional component. This is a code that demonstrates lack of understanding by the partners at an empathic level. In another illustration of this code (TK7-58.13-58.16), Tony is being prompted to paint on paper, in conjunction with two staff. However, his mouth opens wide until he grimaces, his head turns away from the paper, and he cries. Neither staff demonstrates recognition of the indication that Tony does not want to paint at this point, as they both prompt him to continue to hold the brush and apply it to the paper.

\section{Dimension 2: Cooperation}

Table 3 illustrates the second dimension of attuning: cooperation, which calibrates the degree of cooperation between the communication partners. A high level of positive attuning is evident when both partners cooperate together in pursuit of a common purpose. One of the incidents upon which the code attuning single was based, takes place where one partner accepts the wishes of the other. In this instance, John has been 


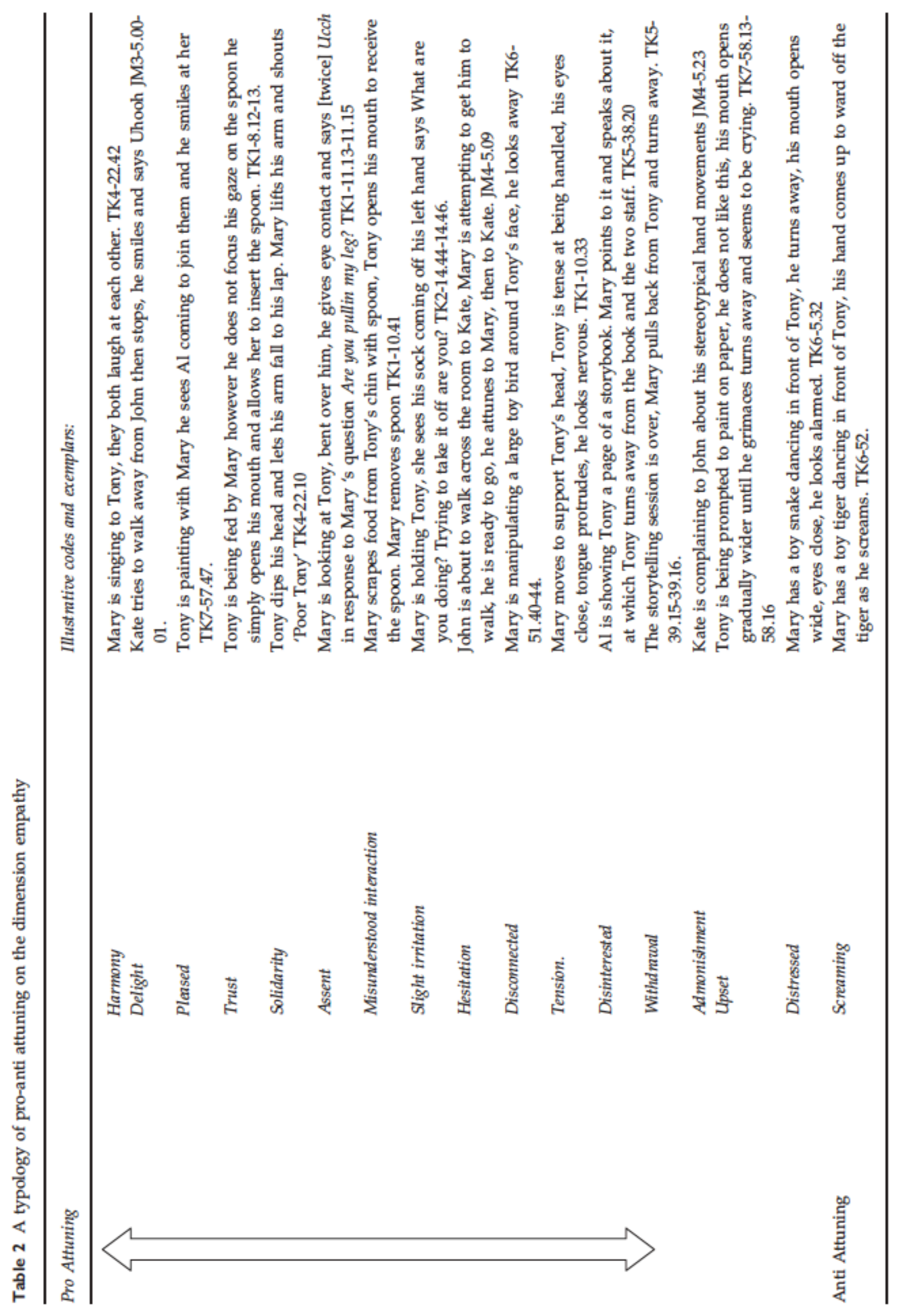


Table 3 A typology of positive - negative attuning on the dimension of cooperation

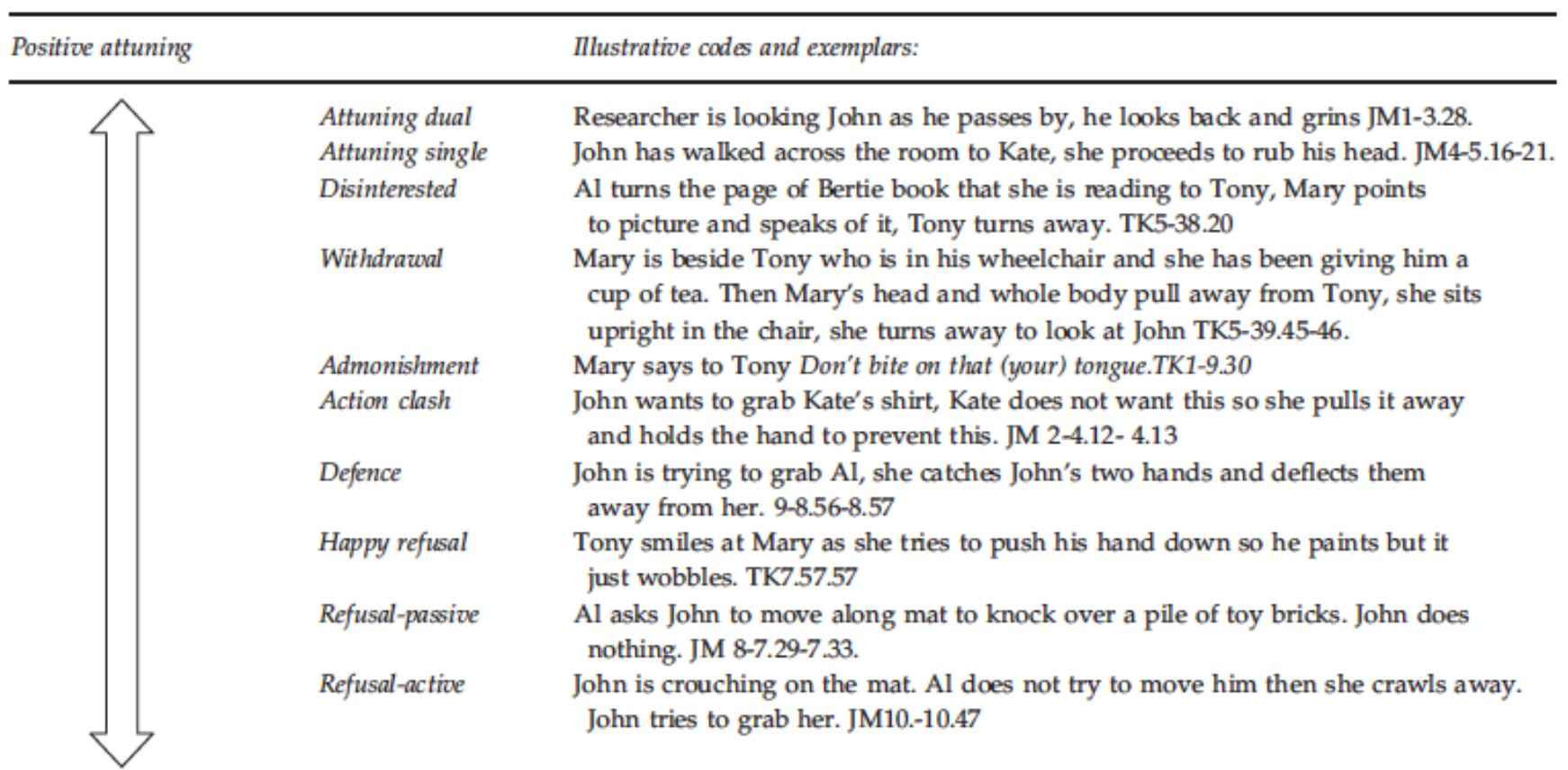

Negative attuning

induced to walk across the room to meet Kate. She rubs his head and he reacts by vocalizing and smiling (JM 5.16-5.21). By contrast, negative attuning occurs when the goals of both partners are in opposition to each other and where they 'refuse' to cooperate. It is based on incidents such as where Mary is trying to feed Tony with a spoon, he pushes his tongue out and forces the spoon away from his mouth (TK2-14.14-16).

Some examples illustrate decreasing levels of cooperation (see Table 3). The code disinterested is, in part, based on an incident where $\mathrm{Al}$ is showing Tony a page of a storybook. Mary points to it and speaks about it, at which Tony turns away from the book and the two staff (TK5-38.20). Withdrawal by contrast is concerned with the removal of cooperation in the interaction. In another incident, Mary is beside Tony who is in his wheelchair and she has been giving him a cup of tea. Then, Mary's head and whole body pull away from Tony, she sits upright in the chair and turns away to look at John (TK5-39.45-46). This act signifies a change in the level of cooperation between Mary and Tony and an end to the communication between them.

At the negative end of the continuum of cooperation, there are many codes for refusal. However, a typical code is refusal-active. This is illustrated by an incident where John is sitting on a gym mat. A series of mats cover the floor ahead of him and a large plastic triangle is in front of him. $\mathrm{Al}$ is trying to induce him to crawl through the plastic triangle that is in front of him. John sees $\mathrm{Al}$ approach. She says 'move that bum', he continues to sit cross-legged on the mat; he drops his head, puts his hands in his lap and looks blank (JM87.23-27). Refusal passive is a different code that depicts passive refusal to accede to the demands of the other person. In one such incident, a painting session is in progress and Tony is holding onto a tube of paint. Mary is trying to dislodge Tony's hand from the tube. $\mathrm{He}$ holds on and then rather mischievously seems to celebrate his victory by vocalizing the utterance 'Heh' (TK8-1.00.44).

In some of the interactions analysed, both partners are symmetrically and reciprocally attuned to each other, indicated by codes such as collusion, empathy, assent, contact and close contact. However, attuning can also be asymmetrical. One partner may be highly focused or 'attuned' to another, while the latter may demonstrate far less empathy, to the point of ignoring the partner or refusing to cooperate. One example of such asymmetry occurred in an incident coded the crush. In this incident (JM 2-4.05), John is running across the room to Kate who is on the far side of the room and has her arms open. John is hurrying in her direction, his eyes intently 
fixed on her (suggesting high attuning). Kate is looking at John, as she is waiting for him to arrive, but he has his arms open, is looking at her intently as he nears her. John appears to be very keen to complete the task of running across the room. It appears that Kate is attuned to John but by no means to the same degree, as he is making the physical movement towards her while she simply awaits him. The attuning is imbalanced at this point.

\section{Attuning: Summed up}

Thus, what emerges from the data here is a complex construct of attuning, characterized by relationships along two interfacing continua, one representing empathy and the other cooperation. The degree of attuning can vary along these dimensions, can change rapidly within interactions and can be either symmetrical or asymmetrical across participants in interactions. Three different foundations seem to impact on the attuning process. The first is previous knowledge of patterns of behaviour within the dyad that appear likely to be repeated in the future. The second is an awareness of what is happening in the present interaction and the third is knowledge of anticipated behaviours that are based on current observations. The anticipation of future behaviours based on a learned understanding of previous patterns of communication implies that both communication partners comprehend that interactions occur in patterns and are to some extent predictable. For example, the incidents where Tony is being fed easily (harmony TK1-9.33) and the code crush (JM 2-4.05) referred to above, both suggest that these actions have been done before and the routine is well understood and predicted by the participants. The importance of routines in providing a context for social interaction has also been noted by Johnson et al. (2012).

\section{Discussion}

This section locates attuning in the context of the dyadic interaction process, identifies some related concepts in the field and considers some implications of the findings.

\section{The significance of attuning for the interaction process}

Attuning as proposed here shares many similarities with concepts such as attunements, sensitive responsibility and some elements of the process of intensive interaction. All attempt to describe how two people align emotionally and behaviourally to achieve understanding. Stern (1985) views attunement in this light. Heidegger (1998) regards attunements as central to the identification of a person's intrapersonal life (their Dasein). Attunements also define the relationship a person may have with the world (Miller 2005). If the conflation of these concepts can be accepted, then attuning is the gerund that dictates the operationalization of attunements. In other words, attunements are individual events that punctuate the attuning process; they are separate steps in the dynamic process of attuning. Attuning may therefore be construed as a process that regulates how each person engages with the world around him or herself and specifically with others in the interaction process.

Dyadic attuning takes place in the context of an understanding that communication is not linear but that it involves a series of reciprocal feedback loops that operate continually. There is ongoing interaction at all times between two people in the one communication space and interaction may register a higher or lower level of attuning at any particular time. In attuning, both participants are equal: attuning is not 'owned' by either participant and cannot be imposed by one participant on the other. Each participant has the same potential for attuning to their partner, creating a power balance that is often lacking in descriptions of interactions of people with PIMD. The attuning model of communication is termed a continuous process model (Fogel 1993) and it suggests:

- That each person in the dyad creates information by engaging in the interaction process.

- That the interaction process involves an ongoing interplay of perception of what the other is doing, creating information for the individual who may then act upon that perception of created information.

- That meaning is constructed from the particular information that is perceived by each person in the dyad.

- That each perception and each piece of information generated by it is regulated by attuning.

\section{Attuning and related processes}

Attuning is not a process that is widely named in the intellectual disability literature. However, there are two other processes that are quite similar and one therapeutic intervention that appears to be related.

Sensitive responsibility is the empathic reading of another's communications. Wilder \& Granlund (2003) 
examined the perceptions of the dyadic interaction of seven caregivers of children who were aged between 3 and 7 years who communicated at the pre-symbolic level. They found that 'caregivers show sensitive responsibility in interaction' defined as 'reading the children's signals and leading the interaction according to what the children's capabilities are at that moment' (Wilder \& Granlund 2003:565). The authors also note that the caregivers explained that they are 'sensitive to changes in the immediate interaction situation' (Wilder \& Granlund 2003:566) (i.e. within the model proposed here, they are highly attuned). These authors say less about the capabilities of the children, who are described as not displaying intentionality in their interactions.

A similarly named but contrasting process describes a certain empathy that is ascribed to both communicators in the dyadic interaction, is 'sensitive responsiveness,' referring to the way partners perceive each other's signals accurately and correspondingly respond to each other' (Hostyn \& Maes 2009:304). The accurate cognitive perception of another's communication signals is one element of attuning; in addition, attuning as proposed here incorporates an affective aspect. Hostyn and Maes note that communication requires an emotional (affective) component. They also discuss 'co-regulation' as a factor in the dyadic interaction process, noting that it brings together 'ideas of mutuality, reciprocity and turn taking' (Hostyn \& Maes 2009:305). Co-regulation is very similar to the code harmony outlined above, which indicates the highest level of pro-attuning. Joint attention is the fourth element that plays a part in the interaction process, according to Hostyn and Maes. In combination, the concepts of co-regulation, an emotional element and sensitive responsiveness suggest a similar process to that of attuning. However, attention, a core element in sensitive responsiveness, is construed in the theory of attuning as operating in tandem with, but separately to, the process of attuning. Attention is seen as a different step of the process, related to attuning but not part of it. It would appear that sensitive responsibility and sensitive responsiveness are static concepts, that is, they describe a quality that the individual possesses that facilitates communication. By contrast, attuning is dynamic, changing as communication changes. It is therefore possible to calibrate the level of attuning that a communicator is demonstrating at any one moment. However, attuning is also a driver for communication, in that the degree of attuning of one individual to another at any one moment affects the level of understanding, cooperation and communication that is achieved at that point. All three concepts (sensitive responsibility; sensitive responsiveness and attuning) suggest that sensitivity is a prerequisite for good communication; however, only attuning addresses the communicative ebb and flow that characterizes interaction in the dyad. This processual dynamic is also evident in the related therapeutic intervention, namely, intensive interaction.

\section{Intensive interaction}

Intensive interaction (Nind \& Hewett 2005) is a widely accepted intervention, which applies principles based upon the empathic nature of the mother-infant dyad, to the problem of how to communicate with people who have severe communication difficulties. A central plank of this approach is the development of mutually acceptable interactive games in which the person with PIMD is encouraged to take the lead (Nind \& Hewett 2005). There is research evidence that intensive interaction impacts individuals with profound intellectual disability by promoting positive interactions, vocal imitations and looking behaviours (gaze) (Samuel et al. 2008). Infusing intensive interaction is the quality of empathy. Empathy, as proposed here, is one dimension of attuning. Solidarity, reassurance and trust are some of the codes that comprise a central element of attuning. These codes imply a sense of mutual valuing which also appears to characterize effective intensive interaction. Attuning and intensive interaction converge where both describe optimal states of communication, perhaps best explained as a state of 'being with' the other person (Firth et al. 2010:58). However, attuning differs from intensive interaction in that it also registers states of asymmetrical interaction, where the degree of sociability is anything but equivalent. To sum up, attuning shares some fundamental characteristics with intensive interaction. Both suggest that communication works best when both participants share an equality of control. Both make reference to empathy, to 'being with' the communication partner. However, attuning as proposed here extends the concept of attuning to a complex, dynamic process incorporating and integrating dimensions of empathy and cooperation that are themselves in constant states of flux.

To conclude, attuning is a process that resonates with many related concepts in the recent intellectual disability literature. It differs from intensive interaction and from sensitive responsiveness in that attuning encompasses interaction that is highly empathic as well as interaction that is deeply disjointed and un-empathic. 
Attuning offers a theory that describes and predicts behaviour across all forms of interaction. It thus differs considerably from sensitive responsiveness and intensive interaction. The theory of attuning can inform practice and assist in developing understanding of how interaction works but is also a process that is new, with potential that is yet to be discovered. Attuning is a mutual process. Each participant has the same potential for attuning to their partner. Attuning explains how each person in the dyad interacts in a power neutral context. It does not rely on power being tacitly handed back by one participant to the other; instead, it takes as its basic assumption that communicative power is shared from the outset.

\section{The Implications of the Study}

\section{Implications for method}

The primary innovation of the study has been in the analysis of microdata derived from detailed descriptions of non-verbal and verbal behaviours in video-recorded interactions, using classic grounded theory. The evidence that is there to be discovered is predominantly manifested as non-verbal behaviours and comprises subtle behavioural changes that are difficult to identify (Mitchell \& Van DerGaag 2002), behaviours that may not be remarked because of their ordinariness (Finlay et al. 2008) and behaviours that occur very rapidly (Shimmerlik 2008). It is through the collection of data that is to a great extent unseen because of its smallness and its unremarkableness that the process of attuning has been identified and it is through the application of grounded theory to the analysis of that data that a theory has emerged (see Griffiths (2013) for further elaboration).

\section{Implications for practice}

This study has found that two people who have severe/profound intellectual disability and staff who interact with them have a capacity to attune to each other, using the same processes. This capability has not been explicitly identified in the literature previously. The theory proposes that attuning applies equally to those with disabilities as well as those without intellectual disability. There are certain implications that follow. First, the free-flowing dyadic nature of interaction is understood by the participants as being the arena where they can communicate. Second, it is possible for a person with complex disabilities to ascertain the 'meaning' of another person. Third, the process by which they ascertain that meaning is the same for both participants, namely, attuning. Implicit in the attuning process is that communication between those with severe and profound intellectual disability and their communication partners should be understood as an interaction of equals, who display their communications in different ways. Both communication partners engage in the process and both attempt to use the process to attain their goals. Attuning as a theory suggests that both partners display equal degrees of agency in communication. Therefore, to take an attuning perspective is to comprehend that both partners in the dyad exert equal degrees of agency and power. Recognizing this implies that the practice of those who support people with PIMD will be one of mutuality, where a mutual esteem is written into all that takes place between the person with PIMD and the other, with the effect that mutual understanding is enhanced and the quality of life is raised for both.

\section{Limitations}

This was an inductive research study that developed theory from qualitative data. That data has some limitations in that it was primarily based upon the analysis of two dyads. In descriptive terms, there is no possibility to generalize from such a limited sample. However, grounded theory assumes that a theoretical framework applies to the context from which it was derived, as long as data do not emerge that makes the theory unworkable. In that sense, the theory of attuning is applicable to the substantive area, a testable theory and a work in progress. Lastly the long period of time that data transcription and analysis requires is noted as being not necessarily a limitation, but a methodological caution.

\section{Conclusion}

This study revealed that people with severe and profound intellectual and multiple disability have a functional ability to engage in communication and that they do this in tandem with their communication partner. The study supports recent research, suggesting that a timely opportunity has arisen to discover more about the ways in which people with complex disabilities communicate, function and understand their interpersonal life. The challenge is to find ways in which this knowledge can be developed to understand 
what people with PIMD think and how they make meaningful choices and thereby offering them a chance to assert autonomy in their lives to achieve the type of living that they wish.

\section{Correspondence}

Any correspondence should be directed to Colin Griffiths, The School of Nursing and Midwifery, Trinity College, 24 D'Olier Street. Dublin 2. Ireland (e-mail: colin.griffiths@tcd.ie)

\section{References}

Bradshaw J. (2001) Communication partnerships with people with profound and multiple learning disabilities. Tizard Larning Disability Review 6, 6-15.

Bunning K. (1996) Development of an individualised sensory environment for adults with learning disabilities and an evaluation of its effects on their interactive behaviours. Doctoral Thesis. City University, London.

Bunning K. (1998) To engage or not to engage? Affecting the interactions of learning disabled adults. International Joumal of Language and Communication Disonders 33, 386-391.

Charmaz K. (2006) Constructing Grounded Theory: A Practical Guide Through Qualitative Analysis. Sage Publications, London.

Coia P. \& Handley A. J. (2008) Developing relationships with people with profound learning disabilities through intensive interactions. In: Making Contact: Promoting Social Interaction for Individuals With Communicative Impairments (ed. S. Zeedyk), pp. 102-118. Jessica Kingsley, London.

Duchscher J. E. B. \& Morgan D. (2004) Grounded theory: reflections on the emergence $\mathrm{v}$ forcing debate. Journal of Advanced Nursing 48, 605-612.

Finlay W. M. L., Anataki C. \& Walton C. (2008) A manifesto for the use of video in service improvement and staff development in residential services for people with learning disabilities. British Journal of Larning Disabilities 36, 227-231.

Firth G., Berry R. \& Irvine C. (2010) Understanding Intensive Interaction. Context and Concepts for Professionals and Families. Jessica Kingsley, London.

Fletcher P. \& Garman M. (1995) Transcription, segmentation and analysis: corpora from the language impaired. In: Spoken English on Computer (eds G. Leech, G. Myers \& J. Thomas), pp. 116-127. Longman Press, Essex.

Fogel A. (1993) Two principles of communication: co-regulation and framing. In: New Perspectives in Early Communication Development (eds J. Nadel \& L. Camaioni), pp. 9-22. Routledge, London.

Forster S. (2011) Affect attunement in communicative interactions between adults with profound intellectual and multiple disabilities and support workers. Doctoral thesis. Monash University. Victoria.
Forster S. \& Iacono T. (2008) Disability support workers' experience of interaction with a person with profound intellectual disability. Joumal of Intellectual and Developmental Disability 33, 137-147.

Garman M. (1989) The role of linguistics in speech therapy: assessment and interpretation. In: The Functional Evaluation of Language Disorders (eds P. Grunwell \& A. James), pp. 29-58. Croom Helm, London.

Glaser B. (1998) Doing Grounded Theory: Issues and Discussions. Sociology Press, Mill Valley, CA.

Glaser B. \& Strauss A. (1967) The Discovery of Grounded Theory: Strategies for Qualitative Research. Aldine de Gruyter, New York.

Grice H. P. (1999) Logic and conversation. In: The Discourse Reader (eds A. Jaworski \& N. Coupeland), pp. 67-77. Routledge. London.

Griffiths C. (2013) Using grounded theory to analyse qualitative observational data that is obtained by video recording. The Grounded Theory Review 12, 26-36.

Grove N., Bunning K., Porter J. \& Olsson C. (1999) See what I mean: interpreting the meaning of communications by people with severe and profound intellectual disabilities. Journal of the Applied Research in Intellectual Disabilities 12, 190-203.

Healy D. \& Noonan-Walsh P. (2007) Communication among nurses and adults with severe and profound intellectual disabilities. Journal of Intellectual Disabilities 11, 127-141.

Heidegger M. (1998) What is metaphysics. In: Pathmarks (eds D. F. Krell \& W. McNeill), pp. 82-96. Cambridge University Press, Cambridge.

Hewett D. \& Nind M. (1998) Introduction: recent developments in interactive approaches. In: Interaction in Action. Reflections on the use of Intensive Interaction (eds D. Hewett \& M. Nind), pp. 1-23. David Fulton, London.

Hogg J., Reeves D., Roberts J. \& Mudford O. C. (2001) Consistency, context and confidence in judgments of affective communication in adults with profound intellectual and multiple disabilities. Journal of Intellectual Disability Research 45, 18-29.

Hostyn I. \& Maes B. (2009) Interaction between persons with profound intellectual and multiple disabilities and their partners: a literature review. Journal of Intellectual and Developmental Disability 34, 296-312.

Hostyn I., Petry K., Lambrechts G. \& Maes B. (2011) Evaluating the quality of the interaction between persons with profound intellectual and multiple disabilities and direct support staff: a preliminary application of three observation scales from parent-infant research. Journal of Applied Research in Intellectual Disabilities 24, 407-420.

Hughes R. P., Redley M. \& Ring H. (2011) Friendship and adults with profound intellectual and multiple disabilities and English disability policy. Journal of Policy and Practice in Intellectual Disabilities 8, 197-206.

Johnson H., Douglas J., Bigby C. \& Iacono T. (2011) The challenges and benefits of using participant observation to 
understand the social interaction of adults with intellectual disabilities. Augmentative and Alternative Communication 27, 267-278.

Johnson H., Douglas J., Bigby C. \& Iacono T. (2012) Processes that underpin positive relationships for adults with severe intellectual disability. Journal of Intellectual and Developmental Disability 37, 324-336.

Kaiser A. P. \& Goetz L. (1993) Enhancing communication with persons labeled severely disabled. Journal of the Association for the Severely Handicapped 18, 137-142.

McLean J., McLean L, Brady N. \& Etter R. (1991) Communication profiles of two types of gesture using non verbal persons with severe to profound mental retardation. Journal of Speech and Hearing Research 34, 294-308.

McLean L., Brady N., McLean J. \& Behrens G. N. (1999) Communication forms and functions of children and adults with severe mental retardation in community and institutional settings. Joumal of Sperch and Hearing Research 42, 231-240.

Miller M. R. (2005) A joyful path to Dasein. New Blackfriars 86, 379-388.

Mitchell J. \& Van DerGaag A. (2002) Through the eye of the Cyclops: evaluating a multi-sensory intervention programme for people with complex disabilities. British Journal of Learning Disabilities 30, 159-165.

Nakken H. \& Vlaskamp C. (2007) A need for a taxonomy for profound intellectual and multiple disabilities. Joumal of Policy and Practice in Intellectual Disabilities 4, 83-87.

Nilsson L. (2011) Using video methods in grounded theory research. In: Grounded Theor: The Philosophy, Method and Work of Bamey Glaser (eds V. B. Martin \& A. Glynnild), pp. 103116. Brown Walker Press, Boca Raton, FL.

Nind M. \& Hewett D. (2005) Access to Communication: Developing Basic Communication With People who Have Severe Leaming Difficulties. David Fulton, London.

Ochs E. (1979) Transcription as theory. In: Developmental Pragmatics (ed. B. B. Schieffelin), pp. 43-72. Academic Press, London.

Samuel J., Nind M., Volans A. \& Scriven I. (2008) An evaluation of intensive interaction in community living settings for adults with profound intellectual disabilities. Journal of Intellectual Disabilities 12, 111-126.

Schonfeld A. H. (1992) On paradigms and methods: what do you do when the ones you know don't do what you want them to? Issues in the analysis of data in the form of videotapes. The Joumal of Learning Sciences 2, 179-214.

Shimmerlik S. (2008) The implicit domain in couples and couples therapy. Psychoanalytic Dialogues 18, 371-389.

Stephenson J. \& Dowrick M. (2005) Parents' perspectives on the communication skills of their children with severe disabilities. Journal of Intellectual and Developmental Disability $30,75-85$.

Stern D. (1985) The Interpersonal World of the Infant. Karnac Books, London.

Strauss A. \& Corbin J. (1990) Basics of Qualitative Research: Techniques and Procedures for Developing Grounded Theory. Sage, London.

Wilder J. \& Granlund M. (2003) Behaviour style and interaction between seven children with multiple disabilities and their caregivers. Child: Care, Health and Development 29, 559-567. 